\title{
Westerwoldin raiheinän (Lolium multiflorum v. westerwoldicum) siementuotantomahdollisuudet Suomessa
}

\author{
Markku Niskanen ${ }^{1)}$ ja Oiva Niemeläinen ${ }^{2)}$ \\ ${ }^{1)}$ MTT Etelä-Pohjanmaan tutkimusasema, Alapääntie 104,61400 Ylistaro, markku.niskanen@mtt.fi \\ ${ }^{2)}$ MTT Kasvintuotannon tutkimus, 31600 Jokioinen, oiva.niemelainen@mtt.fi
}

\section{Tiivistelmä}

Etelä-Pohjanmaan tutkimusasemalla Ylistarossa ja Kasvintuotannon tutkimuksella Jokioisilla tutkittiin westerwoldin raiheinän siementuotantomahdollisuuksia maassamme. Tutkimuksen tavoitteena oli selvittää eri lajikkeiden siementuotantokykyä sekä siemenen tuottamiseen liittyvin riskien hallintaa. Tässä esityksessä esitellään tuloksia neljästä lajikekokeesta sekä yhdestä Ylistarossa tehdystä puintiaikakokeesta. Kokeet toteutettiin vuosina 2001-2003.

Westerwoldin raiheinästä voidaan tuottaa Suomessa korkeita siemensatoja. Parhaista lajikkeista saavutettiin yli $1500 \mathrm{~kg}: n$ hehtaarisatoja. Myös siemenen laatu oli riittävän hyvä. Kaikkien neljän kokeen keskimääräinen itävyys oli 88 prosenttia. Kaikki tutkitut lajikkeet olivat riittävän aikaisia.

Puintiaikakokeessa varisemistappiot nousivat yli 30 prosenttiin, kun puinti lykkääntyi tuleentumisen alusta 1-2 viikkoa. Ensimmäinen puintiaika tuotti kaikkein matalimman sadon ja viimeinen puintaika korkeimman sadon. Ensimmäisen ja kolmannen puintiajan satoero oli 170 kiloa, mutta ero ei kuitenkaan muodostunut tilastollisesti merkitseväksi. Itävyyteen kahta viikkoa myöhäisempi puinti vaikutti selvästi negatiivisesti.

Puintia ei kannata lykätä kovin paljon kun pääosa tähkistä on tuleentunut, vaikka sato saattaa vielä kasvaa. Myös säiden aiheuttamat riskit kannattaa huomioida puinnin ajoituksessa. Kovat sateet ja tuulet voivat lisätä varisemista huomattavasti. Puinnin myöhästyttäminen lisää myös laaturiskiä ja esimerkiksi syksyn yöhallat saattavat vaurioittaa siementen itävyyttä. Liikaa siementen varisemista kannattaa välttää, sillä varisseet siemenet voivat muodostua seuraavana vuonna merkittäväksi rikkakasviongelmaksi.

Westerwoldin raiheinän kasvuaika on pitkä, ja normaalisti puinti on elokuun loppupuolella, mikäli kylvötöihin päästään hyvissä ajoin toukokuussa. Pitkä kasvuaika lisää viljelyriskiä raiheinän siementuotannossa, varsinkin epätasaisesti tuleentuneessa kasvustossa. Siementuotannossa kannattaa suosia aikaisia lajikkeita sekä keskittää tuotanto suotuisille viljelyalueille, joissa pelloille päästään mahdollisimman aikaisin keväällä.

Suurimmaksi ongelmaksi westerwoldin raiheinän siementuotannossa muodostui tasaisen ja tasaisesti tuleentuvan kasvustoon aikaansaaminen. Tulosten valossa kasvuston tasaisen tuleentumisen varmistaminen on tärkeää, jotta vältytään varisemistappioilta ja saadaan laadukas siemensato alhaisilla kuivauskustannuksilla. Lisää tutkimusta tarvitaan mm. kylvötiheyden, lannoituksen ja kasvunsääteiden vaikutuksesta kasvuston tasaisen tuleentumisen varmistamiseksi

Avainsanat: Westerwoldin raihienä, siementuotanto, itävyys, lajikkeet, puintiaika, siemensato 


\section{Johdanto}

Suomessa viljellään kahta eri yksivuotisen raiheinän muunnosta: Italian- ja westerwoldin raiheinää. Näistä lajeista on yleisemmin viljelty Italian raiheinä (Lolium multiflorum). Se on oikeastaan monivuotinen laji, mutta se ei talvehdi meidän ilmastossamme. Laji ei myöskään tuota kortta eikä tähkää ensimmäisenä kasvuvuonna, joten sen siementuotanto ei ole mahdollista Suomessa. Westerwoldin raiheinä (Lolium multiflorum. westerwoldicum) sen sijaan tuottaa tähkän jo kylvövuonna, joten sen siementuotanto onnistuu Suomessakin

Yksivuotisia raiheiniä käytetään laidun- tai niittorehukasveina, joko puhtaina kasvustoina, tai seoksina esimerkiksi vihantaviljojen kanssa. Poudanarkuutensa vuoksi ne sopivat parhaiten viljeltäväksi hikevillä kivennäis- ja turvemailla. Niitä viljellään eniten Itä- ja Pohjois-Suomessa.

Italian raiheinän siementä tuotiin Kasvintuotannon tarkastuskeskuksen tilaston mukaan siementuotantokaudella 2003-2004 Suomeen 275 tonnia. Westerwoldin raiheinän siementä tuotiin vastaavana ajanjaksona 34 tonnia. Westerwoldin raiheinän siementä tuotettiin Suomessa vuonna 2003 seitsemän hehtaarin alalla ja serdifioitua siementä tuotettiin $5600 \mathrm{~kg}$. Siementuotantoala on vaihdellut vuosien kuluessa. Enimmillään se on ollut muutamia kymmeniä hehtaareja.

Westerwoldin raiheinä on heinäkasviksi hyvä siementuottaja. Sen siementuotanto alaa voitaisiin lisätä vastaamaan kotimaista siementarvetta. Tulevaisuudessa kiinnostus yksivuotisten raiheinien viljelyyn tulee varmasti kasvamaan karjakoon kasvaessa ja sisäruokinnan yleistyessä, jolloin viljelyssä tarvitaan nopeasti satoa tuottavia heinälajeja. Nopeakasvuisena heinänä westerwoldin raiheinä sopii tähän tarkoitukseen hyvin.

Westerwoldin raiheinän siementuotantoa on tutkittu suhteellisen vähän. Lähes kaikki yksivuotisen raiheinän siementuotantotutkimus on tehty italianraiheinälle. Erilaisen kasvurytmin ja tavan vuoksi näiden tutkimusten tuloksia on vaikea soveltaa westerwoldin raiheinän siementuotantoon Suomen kasvuoloissa.

Tässä tutkimuksessa selvitettiin muutamien rehuviljelyssä käytettyjen westerwoldin raiheinälajikkeiden siementuotanto-ominaisuuksia Suomessa. Toisessa kokeessa tutkittiin puintiajankohdan vaikutusta siemensatoon ja variemsitappiohin.

\section{Aineisto ja menetelmät}

Westerwoldin raiheinän lajikkeiden siementuotanto kykyä tutkittiin neljässä lajikekokeessa, jotka toteutettiin MTT:n Kasvintuotannon tutkimuksella Jokioisilla ja Etelä-Pohjanmaan tutkimusasemalla Ylistarossa vuosina 2002 ja 2003. Lajikekokeisiin valittiin viisi aikaisinta ja rehuviljelyssä satoisinta lajiketta (taulukko 1). Ne valittiin aikaisemmin tehtyjen siementuotantokokeiden perusteella (Niemeläinen ja Niskanen 2003).

Lajikekokeet toteutettiin satunnaistettujen lohkojen kokeena. Kokeessa oli neljä kerrannetta ja koeruudun koko oli 8-10 m X 1,5 m. Typpilannoitus $80 \mathrm{~kg} / \mathrm{ha}$ annettiin sijoituslannoituksena kylvön yhteydessä. Rikkakasvit torjuttiin kokeesta käyttäen nurmikasvien siementuotannossa hyväksyttyjä rikkakasvien torjunta aineita.

Kasvukauden aikana kasvustosta havainnoitiin tähkinnän alkaminen. Heinäkuun lopussa otettiin kasvustonäytteet, joista laskettiin tähkien lukumäärä neliömetriä kohti sekä tähkylöiden määrä per kasvi. Kokeet puitiin koeruutupuimurilla. Puinti pyrittiin tekemään sellaisessa vaiheessa, että pääkasvusto oli tuleentunut. Puinnin yhteydessä määriteltiin puintikosteus kuvaamaan lajikkeiden tuleentumisastetta. Lajittelun jälkeen määriteltiin puhtausprosentti ja kosteus. Hehtaarisadot korjattiin 14 prosentin kosteuteen.

Sadosta määriteltiin tuhannen siemenen paino ja itävyys. Itävyys määritettiin Jakobsenin altaassa paperin päällä. Itäneet siemenet laskettiin 5 vrk:n ja 14 vrk:n kuluttua itämään laittamisesta.

Toisessa kokeessa tukittiin westerwodin raiheinän puintiajan vaikutusta siementen varisemistappioihin. Se toteutettiin Ylistarossa Etelä-Pohjanmaan tutkimusasemalla vuonna 2001. Kokeessa oli kolme eri puintiaikaa. Lajikkeena oli Pollanum. Kylvö ja muut kasvuston hoitotoimenpiteet tehtiin kuten lajikekokeessa. Heinäkuussa kasvustoon asetettiin kuhunkin ruutuun kahteen riviväliin $50 \mathrm{~cm}: n$ pituiset muoviset kourut siementen varisemismäärän selvittämiseksi.

Ensimmäinen puinti oli 23.8, toinen puinti 29.8. ja kolmas puinti 6.9. Ennen puintia kasvustossa olleet kourut tyhjennettiin varisseista siemenistä. Niiden määrä punnittiin sekä määritettiin kosteus. 
Puidusta sadosta määriteltiin, puintikosteus, puhtaus, kuiva-aine, 1000 siemenen paino ja itävyys lajikekokeen tapaan.

Molempien kokeiden tilastolliset analyysit tehtiin SAS-ohjelman MIXED proseduurilla.

\section{Tulokset ja tulosten tarkastelu}

\section{Lajikekoe}

Kahden vuoden keskisato oli Ylistarossa 1410 kg/ha ja Jokioisilla 1180 kg/ha (Taulukko 1). Vuonna 2002 keskisato oli molemmilla koepaikoilla suurempi kuin vuonna 2003. Suurimmat sadot saavutettiin Ylistarossa vuonna 2002, jolloin lajikkeiden keskimääräinen sato oli $1470 \mathrm{~kg} / \mathrm{ha}$. Vuonna 2003 Jokioisilla lajikekokeen keskisato oli pienin, $1120 \mathrm{~kg} / \mathrm{ha}$.

Taulukko 1. Lajikekokeiden tulokset Ylistarossa ja Jokioisilla vuosina 2002-03. Samalla kirjaimella merkityt sarakettaiset keskiarvot eivät eroa merkittävästi toisistaan

\begin{tabular}{|l|c|c|c|c|c|c|c|}
\hline & \multicolumn{3}{|c|}{ Jokioinen } & \multicolumn{4}{c|}{ Ylistaro } \\
\hline Lajike & Sato kg/ha & $\begin{array}{c}\text { Itävyys } \\
\%\end{array}$ & $\begin{array}{c}\text { Tsp } \\
\text { gr }\end{array}$ & $\begin{array}{c}\text { Sato } \\
\mathrm{kg} / \mathrm{ha}\end{array}$ & $\begin{array}{c}\text { Puinti- } \\
\text { kosteus } \%\end{array}$ & $\begin{array}{c}\text { Itävyys } \\
\%\end{array}$ & $\begin{array}{c}\text { Tsp } \\
\text { gr }\end{array}$ \\
\hline Pollanum & $1510 \mathrm{a}$ & 91 & $5,0 \mathrm{~b}$ & $1560 \mathrm{a}$ & $32,4 \mathrm{a}$ & 89 & $5,6 \mathrm{~b}$ \\
\hline Jivet & $1230 \mathrm{~b}$ & 88 & $4,9 \mathrm{~b}$ & $1440 \mathrm{a}$ & $35,6 \mathrm{~b}$ & 88 & $5,8 \mathrm{a}$ \\
\hline Contado & $1060 \mathrm{~b}$ & 88 & $4,8 \mathrm{~b}$ & $1380 \mathrm{a}$ & $36,8 \mathrm{~b}$ & 86 & $5,4 \mathrm{bc}$ \\
\hline Lemnos & $1060 \mathrm{~b}$ & 90 & $5,5 \mathrm{a}$ & $1140 \mathrm{~b}$ & $37,8 \mathrm{~b}$ & 86 & $5,9 \mathrm{a}$ \\
\hline Andy & $1050 \mathrm{~b}$ & 89 & $4,9 \mathrm{~b}$ & $1510 \mathrm{a}$ & $38,5 \mathrm{~b}$ & 88 & $5,2 \mathrm{c}$ \\
\hline & $* * *(\mathrm{p}<0,001)$ & & $* * *(\mathrm{p}<0,001)$ & $* *(\mathrm{p}<0,01)$ & $* *(\mathrm{p}<0,01)$ & & $* * *(\mathrm{p}<0,001)$ \\
\hline
\end{tabular}

Pollanum oli muita lajikkeita satoisampi. Sen keskisato neljässä kokeessa oli $1530 \mathrm{~kg} / \mathrm{ha}$. Vuonna 2002 Ylistarossa Pollanumin sato oli $1790 \mathrm{~kg} / \mathrm{ha}$, mikä oli yksittäisen kokeen suurin saavutettu sato. Aikaisemmissa koesarjoissa (Niemeläinen ja Niskanen 2003) Pollanumista on saatu yli $2000 \mathrm{~kg}: \mathrm{n}$ hehtaarisato.

Muiden lajikkeiden keskinäiset satoerot olivat pienempiä. Lemnoksen sato oli koesarjan alhaisin $1100 \mathrm{~kg} / \mathrm{ha}$. Ylistarossa sen keskisato oli merkitsevästi muita lajikkeita pienempi.

Siemenen keskimääräinen itävyys neljässä kokeessa oli 88 prosenttia. Ylistarossa kahden vuoden keskimääräinen itävyys oli 87 prosenttia ja Jokioisilla 89 prosenttia. Jokioisilla ei ollut vuosien välillä eroa itävyyksissä. Ylistarossa vuonna 2002 siementen keskimääräinen itävyys oli 90 prosenttia, mutta vuonna 2003 kokeen keksimääräinen itävyys oli 6 prosenttiyksikköä pienempi. Lajikkeiden välillä ei ollut itävyyksissä eroja.

Tuhannen siemenen paino (TSP) vaihteli 4,8 grammasta 6,1 grammaan. Lajikkeista Lemnoksen siemen oli keskimäärin suurinta ja Andyn siemen pienintä. Lajikkeiden väliset erot siemenkoossa muodostuivat myös tilastollisesti merkitseviksi (Taulukko 1). Vuonna 2002 siemen oli keskimäärin 0,4 grammaa suurempaa kuin vuonna 2003. Ylistarossa tuhannen siemenen paino oli vuonna 2003 vajaa puoli grammaa suurempi kuin Jokioisilla.

Tulokset osoittavat, että westerwoldin raiheinästä voidaan tuottaa Suomessa varsin suuria satoja. Lajikkeiden välillä on selviä eroja siementuotantokyvyssä. Pollanumin siementä on tuotu Kasvintuotannon tarkastuskeskuksen tilastojen mukaan westerwoldin raiheinästä eniten (Anon 2003) ja ainakin osa tuonnista olisi mahdollista korvata kotimaisella siementuotannolla.

Raiheinän siementuotantoon liittyy kuitenkin ilmastoomme liittyviä riskejä. Korkea itävyys on raiheinän siementuotannossa tärkeää, sillä tuotetulla sadolla ei ole vaihtoehtoista käyttöä. Aikaisempien tulosten mukaan (Niemeläinen ja Niskanen 2003) tuotetun siemenen itävyys saattaa jäädä alhaiseksi. Riskiä voidaan kuitenkin vähentää oikealla viljely- ja kuivaustekniikalla. Siementuotannossa kannattaa suosia aikaisia lajikkeita sekä keskittää tuotanto suotuisille viljelyalueille, joissa pelloille päästään kylvämään aikaisin keväällä. 


\section{Puintiaikakoe}

Puintiaikakokeen keskimääräinen sato oli $1720 \mathrm{~kg} / \mathrm{ha}$. Ensimmäinen puintiaika tuotti kaikkein pienimmän sadon ja viimeinen puintaika suurimman sadon. Ensimmäisen ja kolmannen puintiajan satoero oli 170 kiloa, mutta ero ei kuitenkaan muodostunut tilastollisesti merkitseväksi. Muodostunut kokonaissiemensato, johon laskettiin mukaan puitu sato ja maahan varisseet siemenet oli selvästi suurin toisessa ja kolmannessa puinnissa. Suuri osa muodostuneesta lisäsadosta kuitenkin menetettiin varisemistappiona.

Varisemistappiot olivat pienimmät ensimmäisessä puinnissa, $402 \mathrm{~kg} / \mathrm{ha}$ ja suurimmat kolmannessa puinnissa, $917 \mathrm{~kg} / \mathrm{ha}$. Ensimmäisen ja toisen puinnin välissä satotappiot nousivat yli kaksinkertaisiksi, mutta toisen ja kolmannen puinnin välissä ei varisemistappiossa ollut enää suurta eroa.

Taulukko 2. Puintiajan vaikutus westerwoldin raihienän siemensatoon ja laatuun Etelä-Pohjanmaan tutkimusasemalla vuonna 2001. Samalla kirjaimella merkityt sarakettaiset keskiarvo eivät eroa merkittävästi toisistaan

\begin{tabular}{|l|c|c|c|c|c|c|}
\hline \multirow{2}{*}{ Puintiaika } & Sato & Varisseet & Koksato ${ }^{1)}$ & Puintikosteus & TSP & Itävyys \\
\cline { 2 - 7 } & $\mathrm{kg} / \mathrm{ha}$ & $\mathrm{kg} / \mathrm{ha}$ & $\mathrm{kg} / \mathrm{ha}$ & $\%$ & $\mathrm{gr}$ & $\%$ \\
\hline 1.puinti (23.8) & 1620 & $402 \mathrm{a}$ & $2022 \mathrm{a}$ & 43,1 & 5,5 & $94 \mathrm{a}$ \\
\hline 2.puinti (28.8) & 1750 & $862 \mathrm{~b}$ & $2612 \mathrm{~b}$ & 43,6 & 5,7 & $90 \mathrm{a}$ \\
\hline 3.puinti (6.9) & 1790 & $917 \mathrm{~b}$ & $2707 \mathrm{~b}$ & 44,5 & 5,6 & $86 \mathrm{~b}$ \\
\hline & & $*(\mathrm{p}<0,05)$ & $*(\mathrm{p}<0,05)$ & & & $*(\mathrm{p}<0,05)$ \\
\hline
\end{tabular}

${ }^{1)}$ Koksato=varisseet+sato

Tuhannen siemenen paino oli pienin ensimmäisessä puinnissa ja suurin toisessa puinnissa. Erot eivät muodostuneet tilastollisesti merkitseviksi. Ensimmäisessä puinnissa siemenen itävyys oli paras, 94 prosenttia. Kun puintia viivästytettiin kahdella viikolla, siemenen itävyys aleni 86 prosenttiin. Puintikosteuteen ei korjuun lykkäämisellä ollut vaikutusta.

Hebblethwaite ym. (1980) ovat raportoineet englannin raiheinällä 30 prosentin satotappioita, kun puintia on viivästetty siten, että sadon puintikosteus on alentunut 40 prosentista 30 prosenttiin. Nurminadalla ja italian raiheinällä on raportoitu 20-60 prosentin satotappioita (Jensen 1976, Raja Harum ja Bean 1979).

Tässä tutkimuksessa varisemistappiot nousivat korkeiksi, kun puintia lykättiin myöhemmäksi. Viikon odottelu ensimmäisen puinnin jälkeen kaksinkertaisti varisemisen ja nosti varisemistappion 33 prosenttiin. Tulosten valossa ei puintia kannata lykätä kovin paljon, kun pääosa tähkistä alkaa tuleentua, vaikka sato saattaa hieman lisääntyä. Myös säiden aiheuttamat riskit kannattaa huomioida puinnin ajoituksessa. Kovat sateet ja tuulet voivat lisätä varisemista huomattavasti. Puinnin myöhästyttäminen lisää myös laaturiskiä, ja esimerkiksi syksyn yöhallat saattavat vaurioittaa siementen itävyyttä.

Liika siementen variseminen voi vaikeuttaa viljelykiertoa, kun varisseet raiheinän siemenet seuraavina vuosina itävät muodostaen pellolle rikkakasviongelman.

Westerwoldin raiheinän kasvuaika on pitkä. Normaalina vuonna kasvusto tuleentuu elokuun viimeisellä puoliskolla, mikäli kylvötöihin on päästy hyvissä ajoin toukokuussa. Pitkä kasvuaika lisää viljelyriskiä raiheinän siementuotannossa varsinkin jos kasvusto on epätasaisesti tuleentunut

Tulosten perusteella kasvuston tasaisen tuleentumisen varmistaminen siementuotannossa on ensiarvoisen tärkeää, jotta vältytään varisemistappiolta ja saadaan aikaiseksi laadukas siemensato mahdollisimman alhaisilla kuivauskustannuksilla. Lisää tutkimusta tarvitaan mm. kylvötiheyden, lannoituksen ja kasvunsääteiden vaikutuksesta kasvuston tasaisen tuleentumisen varmistamiseksi.

\section{Johtopäätökset}

Westerwoldin raiheinä tuottaa suuriakin siemensatoja. Pollanum lajikkeesta saatiin yli $1500 \mathrm{~kg}: \mathrm{n}$ keskisato hehtaarilta. Myös siemenen laatu oli riittävän hyvä. Kaikki tutkitut lajikkeet olivat riittävän 
aikaisia tuottaakseen laadukasta siementä kasvuoloissamme. Tulosten valossa westerwoldin raiheinän siementä voitaisiin tuottaa maassamme korvaamaan siementen tuontia.

Puinnin kanssa ei kannata viivytellä, kun pääosa tähkistä on tuleentunut, sillä varisemistappiot voivat muodostua suuriksi. Puinnin viivästyttäminen ei juuri nosta talteen saatua satoa ja laatu saattaa kärsiä, mikäli puintia myöhästytetään. Suuret määrät varissutta siementä muodostaa maahan siemenpakin, joka saattaa muodostua ongelmaksi myöhemmässä pellon käytössä.

Suurin ongelma westerwoldin raiheinän siementuotannossa on riittävän tasaisen ja tasaisesti tuleentuvan kasvustoon aikaansaaminen. Epätasaisesti tuleentunut kasvusto lisää varisemistappiota, hankaloittaa puintia ja lisää kuivauskustannuksia. Lisää tutkimusta tarvitaan mm. kylvötiheyden, kasvunsääteiden ym. viljelytekniikan vaikutuksesta kasvuston versontaan.

\section{Kirjallisuus}

Anon,2003. Siementuotannon vuositilastot 2002-2003. Kylvösiemen 2003/3. s.9-17

Hebblethwaite,P.D.,Wright,D. \& Noble, A. 1980. Some physiogical aspects of seed yield in Lolium perenne L. (perennial ryegrass).In: Hebblethwaite P.D. (ed). Seed Production. Butterworths, London. pp.71-90.

Jensen H.A. 1976. Investigation of anthesis, length of caryopsis, moisture content, seed weight, seed shedding and stripping - Ripeness during development and ripening of a Festuca pratensis seed crop. Acta Agricultura Scandinavia 26: 264-268.

Niemeläinen,O. \& Niskanen, M. 2003.Tuloksia ulkomaisten nurmikasvilajikkeiden siementuotantokyvystä Suomessa. Nurmisiementen tuotanto vientiin tutkimus- ja kehittämishankkeen päätösseminaari. Jokioinen 11.4.2003. Suomen Nurmiyhdistyksen julkaisuja nro. 20. s 8-31.

Raja Harum, R.M. \& Bean, E.W. 1979. Seed development and seed shedding in north Italian ecotypes of Lolium multoflorum. Grass and forage science 34:215-220. 